\title{
General introduction to global justice in a market society
}

The main argument of this book is that although the capitalist mode of production represents the source of an unprecedented accumulation of well-being, and has contributed so far to an increasing extension of human capabilities, it has posed a substantial obstacle to the exercise of individual autonomy, because for most people it has meant the subjection of the individual possibility of obtaining well-being to participation in a market relation - most commonly, a job contract. From this premise, I shall maintain that capitalism exercises a form of structural domination over all those individuals who are excluded from the control of productive assets. Capitalist structural domination, which does not necessarily materialise either in realised coercion or in destitution, consists in the fact that those who can only hire out their labour performance are deprived of any acceptable alternative to seeking sustenance in the market and hence they lack social freedom in the exercise of their basic capabilities. More specifically, I shall neither engage in arguments such as those declaring that at least some people are worse off in terms of income or capabilities than they would be in a pre-capitalist or a hypothetically alternative mode of production, nor shall I seek to demonstrate that people are less secure in the exercise of their basic capabilities than they were before - when they were vulnerable to health, atmospheric and similar risks. Instead, I shall maintain that capitalist structural domination prevents most individuals from exercising their basic capabilities without someone else being willing to rent out their labour performance. This latter fact creates two normative problems. The first one is that this peculiar form of domination can pave the way to economic exploitation, even in highly obnoxious forms. The second one is that capitalist structural domination is a normative concern in itself, because it curtails freedom, regardless of its secondary consequences.

In this book I shall mainly focus on the second problem. With capitalism I refer to an economic system, and more generally a social system, in which the majority of the means of production have been privatised, labour performance has been transformed into a commodity, and the production and the allocation of goods - including the same labour commodity - is entrusted to the market mechanism, that is to say to the logic of supply and demand (Van Parijs 1984; Crouch and Streeck 1997, pp. 1-18; Milanovic 2019, pp. 1-11). This system 
consists of both institutions and norms that safeguard and implement the private property regime and allow for a more or less unhindered functioning of the market mechanism, according to the political interpretation of the role that the public sector should have in regulating the interactions between private agents in the marketplace and in making up for resulting unbalances and loopholes.

The difficulty with the argument I aim to defend, that is to say, that capitalism intrinsically curtails a specific freedom of a specific but large group of individuals - the freedom of those who are excluded from the ownership of private property, from seeking survival in social interactions that are not market-based - is that I also recognise that capitalism promotes freedom overall, at least in a diachronic sense, meaning in comparison with previous social systems. Accordingly, the right 'anti-power' (Pettit 1996) to capitalist structural domination does not consist in the elimination of the source of domination, but rather in the neutralisation of its negative effects through rendering dominated individuals minimally resilient to economic shocks, be they of micro or macro origin. In brief, I shall propose what I have named 'a minimum de-commodification of labour power' (MDL) as a normative principle of justice, stemming from the negative duty not to pose avoidable constraints on the individual autonomy of others. The latter would consist in decoupling a basic set of capabilities from the market nexus.

Moreover, I shall maintain that some characteristics of the global market render MDL a global principle of justice. More precisely, the responsibility for contributing to MDL lies, primarily, with all those individuals who obtain, more or less directly, marginal increases of wealth through commodified workers, that is to say people who are compelled to accept a contract for lack of admissible alternatives. On the other hand, the scope of MDL cannot be delimited by political borders, but rather overlaps the broader extension of capitalist interactions.

In a few words, the common thread of this book is the normative global proviso of a minimum de-commodification of labour power as the 'anti-power' against a form of structural domination that is inherent in the capitalist social system. The corollary is that MDL would contribute to maximising freedom, given that it would render everyone freer within the social system that best promotes freedom overall. More in practice, MDL could be obtained either through granting market-free income or by strengthening welfare provisions. The only prerequisite for a policy measure to effectively promote MDL is that it should be unconditional, meaning that the allocation of its benefits should not be subject to the willingness of the recipient to accept a given job offer, perhaps after having dropped a certain number of other offers, or to take part in work training programmes. 
The logic behind MDL is to safeguard a basic sphere of individual autonomy that is immune from the influence of the market mechanism. We might also say that MDL would grant anyone the right to withdraw from the market - either voluntarily or involuntarily - without suffering a loss of well-being that would jeopardise the very possibility of surviving in a minimally decent manner. Despite being dictated by a normative concern with freedom from systemic domination, which in turn stems from unequal access to the means of production, the implementation of MDL would also have a positive impact on the interactional forms of exploitation that occur in the labour market. Namely, it would set a limit on the asymmetries of power that in most cases characterise the bargaining between those who are selling their labour performance and those others who are interested in buying it. The former would never be obliged to trade their survival for the worst job conditions that a common individual would accept when her basic sustenance is at risk.

There are two main original arguments in this book. The first one is the normative treatment I am proposing of labour commodification, which should be understood along two different levels: in relation to classic theories of global justice and to the way critical theory has commonly analysed, and criticised, 'reification' and alienation. The second one is what I have named the account of 'exploitation without interpersonal domination', according to which capitalist structural domination materialises only in exploitation at the workplace, hence the whole issue of proletarian unfreedom should be properly framed at the systemic level, while the unfair conditions that a given employer imposes on a dominated employee simply reflect the opportunity that the former has to exploit the vulnerability of the latter - but cannot be considered in itself as the source of the same vulnerability and thus of domination.

The text is structured in the following way. In Chapter 1, I propose an analytical definition of labour commodification and seek to explore its philosophical roots. In Chapter 2, I maintain that highly commodified individuals are subject to a form of systemic domination, and I develop the account of 'exploitation without interpersonal domination'. In Chapter 3, I present a theory of global justice based on a minimum de-commodification of labour power, also explaining why I consider it as something new in the cosmopolitan debate. In Chapter 4, I deal with four strong objections usually levelled against cosmopolitan justice: the compatriot priority principle, the coercion view, the allegations of uselessness, and infeasibility.

However, before getting to the heart of the theory I would like to present, I think it is necessary to clarify the nature of the underlying normative argument. Accordingly, in the remaining part of this introduction I shall firstly explain why by adopting as my critical objective the unequal access to the means of production I am advancing a normative claim that is different from the one targeted by positive and negative theories of global justice. Secondly, 
I shall stress that MDL is not intended as an ethical criticism that addresses capitalism 'as a form of life' (Jaeggi 2015, 2018), but rather as a moral argument underpinned by the inviolability of individual autonomy.

\section{RELATIONAL THEORIES OF GLOBAL JUSTICE}

When approaching theories of global justice, the first distinction to be made is the one between practice-dependent and practice-independent accounts (see James 2005; Abizadeh 2007; Sangiovanni 2007, 2008, 2016; Ronzoni 2009; Armstrong 2012, pp. 25-34). The former maintain that global duties of justice are owed in virtue of shared social practices, while the latter assert that duties of justice hold among individuals living in different countries regardless of the existence and of the extent of their interactions. The classic thought experiment for understanding the difference between the two different approaches consists in imagining two communities that are separate and without any possibility of communicating - they can be two islands or two different planets. One is very well off, while the other is very poor. Do you think there exist normative reasons for redistributing wealth from the first towards the second community so as to make the two communities more equal? If you think so, here you have a practice-independent conception of justice; conversely, if you do not think so, this would imply that you embrace a practice-dependent conception of justice.

The typical example of a practice-dependent account of global justice is the global egalitarianism that flourished in the wake of Rawlsian contractualism, which holds that the globalisation of national social systems has reached such a level of interconnection that the normative need emerges to find rules for dividing benefits and burdens of the global economy fairly. More specifically, there are two main contractualist justifications for global justice. One is based on cooperation and draws attention to the fact that there exists a sort of cooperative surplus, meaning that there is more aggregate wealth in - and thanks to - a world in which economic agents who are located in different countries interact continuously, than in a hypothetical or historically antecedent scenario of self-contained local societies. This empirical evidence poses the demand to agree on global principles for splitting the cooperative surplus so as to neutralise the arbitrary advantage or disadvantage of being born in a more or less advantaged country (Pogge 1989; Beitz 1999; Moellendorf 2002; Brock 2009; James 2012), precisely as John Rawls (1999a) sought to propose principles of socio-economic justice, for national societies, that could level out the advantages stemming from those individual factors that he deems morally arbitrary, that is to say, both natural and social assets.

The second justification is based on coercion, and paradoxically it was built on a critique that philosophers such as Thomas Nagel (2005) and Michael 
Blake (2001) moved against global theories of justice. We might also concede, their argument goes, that geographically displaced individuals contribute to making the world better off, at least in aggregative terms. Yet, these individuals are not subjected to the same coercive practices that, for example, exist at the national level and are embodied in both civil and criminal laws. Coercion is one of the preconditions of socio-economic justice, in the sense that a redistribution of resources is the only way through which coercive practices can become acceptable to the worse off, as, for example, to those who are in poverty and are prevented from appropriating someone else's property. Further, rendering coercive practices justifiable is the only way to rid them of the aura of arbitrariness, which in turn could make coercion acceptable from a liberal perspective. Some other philosophers have taken on this theory and have counter-argued that coercion also exists at the global level, either in the form of state border control (Abizadeh 2007, pp. 345-57), or in the practices in use within international organisations that are entrusted with financial stability or trade rules - the latter are apparently non-coercive, since in theory no one obliges a given country to take part in the structure of global trade, for example, but are coercive in practice, because in many cases opting out from the global economy is not a viable option (Valentini 2011).

Global egalitarians usually stick to an empirical premise. Given that they seek to develop their theories as an extension, or more correctly an amendment, of Rawls's contractualism, they maintain that Rawls was correct in the theoretical passages of his moral constructivism, that is to say in the way he sketches the circumstances of justice, the original bargaining situation, and the same rationales guiding the representatives of the bargaining, but he was wrong in interpreting the basic structure of society as overlapping the political borders of states. More precisely, Rawls (1999a, pp. 6-10; 2001, pp. 11-22; 2005, pp. 257-88) describes the basic structure of society as the set of institutions that, in a liberal society, determine the allocation of benefits and burdens of cooperation (e.g. the constitution, the legal and the economic systems, the family and so on). Furthermore, he maintains that the basic structure is the primary site of justice, meaning that the task of the representative taking part in the hypothetical bargaining of the social contract consists in finding the right principles for regulating the institutions that make up the basic structure, rather than the single interactions that take place among the individuals who are subject to these institutions (see also Murphy 1998). In this sense, it would be correct for the social contract to hold that access to public health care should be more or less inclusive, or that income taxes should be more or less progressive, but it would not make sense for the social contract to establish which moral principles should guide two private individuals engaged in a market transaction, or to hold that billionaires should donate a given percentage of their income to one charity rather than another. 
Since the majority of global egalitarians are Rawlsian, they cannot deny the equation between the site of justice and the basic structure of society; hence they can pursue two main paths to defend global principles of justice. The first one consists in arguing that globalisation has extended what Rawls meant with the basic structure beyond national borders, so as to encompass the whole world, and a series of empirical arguments can be deployed in this direction (Scanlon 1973; Pogge 1989; Beitz 1999; Moellendorf 2002; James 2012). It might be argued, for example, that the way capital gets continuously reinvested in different national economies lays the foundations for global circumstances of justice, given that marginal increases of profits are allowed by international passages of semi-laboured products throughout the whole chain of production. It might be added that global trade creates both winners and losers, hence it is morally wrong to allow arbitrary factors, as, for example, the strength of single countries in bargaining trade rules, in determining the extent of gains and losses. Usually, anti-cosmopolitan theorists (at least those contemplating the scope of justice) object that even though global trade, and more generally global flows of capital and products, are obviously a reality, the absence of state-like institutions makes any attempt to extend the scope of justice futile (Blake 2001; Nagel 2005; R. Miller 2005). To this, global egalitarians might either reply that the set of rules administered by financial and trade international organisations has the same urgency of constitutional rules (Beitz 1999, pp. 148-9; see also Valentini 2011), or they might bite the bullet and argue that the basic structure of society is nowadays global because of economic reasons, even though state-like institutions do not exist at the global level (Moellendorf 2002; James 2012).

The second path in defence of global justice consists in conceding even more to anti-cosmopolitans, thus recognising that a global basic structure does not exist, but holding that the basic structure of society is an instrumental condition of justice rather than one of existence (Abizadeh 2007; Ronzoni 2009). More specifically, it might be maintained, as Arash Abizadeh (2007, pp. 325-41) does, that global economic interactions do not reflect the cooperative ideal Rawls had in mind, that is to say interactions that are fair, because we lack those global institutions that might allow mere economic interactions to evolve into cooperative practices. However, it is exactly this lack of global regulations that poses the normative demand for creating global institutions that could render global interactions fair. From this perspective, the site and the scope of justice do not coincide. The former consists of the basic structure of society, which is still local, while the latter refers to all those individuals who take part in interactions that might become fair, and they are not necessarily living within the same country. In sum, Abizadeh concludes, the misalignment between the scope and the site of justice creates a diffuse responsibility for 
a realignment through building up global institutions that allocate the global cooperative surplus fairly.

From these different ways of defending a global scope of justice, which may accompany either a national or a global conception of the site of justice, more or less encompassing principles of justice can be derived (see also Corvino 2019a). Philosophers and theorists such as T.M. Scanlon (1973, pp. 1066-7), Thomas Pogge (1989, pp. 246-59), Charles Beitz (1999, pp. 150-53) and Darrel Moellendorf (2002, pp. 80-86) have argued that if we correct the wrong empirical conception Rawls had of the world, as made of independent states that have reached a lower level of interconnection than the real one, or at least lower than the one we have today, with the theory of justice as fairness, it automatically follows that Rawls's second principle of justice should be global in scope ('social and economic inequalities should be arranged so that they are both (a) to the greatest benefit of the least advantaged persons, and (b) attached to offices and positions open to all under conditions of equality of opportunity' (Rawls 1999a, p. 53)). In particular, they have focused their normative attention on the first part of Rawls's second principle ('social and economic inequalities should be arranged so that they are [...] (a) to the greatest benefit of the least advantaged persons), the so-called 'difference principle', that in their view should become a 'global difference principle'. The latter would imply a global mechanism for redistributing wealth so as to contain global inequalities within the limit in which they are to the advantage of those who are worst off in the world. In other words, in a hypothetical scenario of perfect global equality of wealth, a global difference principle would allow those individuals who live in the most advantaged countries to create inequality of wealth only if this is expected to have a positive impact on the well-being of those other individuals who would be least advantaged. In more practical terms, given that we already live in an unequal world, the global difference principle would require developed economies to make large investments in the development of poorer countries. This can occur either through global institutions, as postulated by Abizadeh, or through international mechanisms that are more voluntary and infringe less on national autonomy.

Some other theorists, in particular Simon Caney (2001; see also Barry 1973, pp. 128-33), have focused instead on the principle of global equality of opportunity, which is enshrined in the second part of Rawls's second principle of justice ('social and economic inequalities should be arranged so that they are [. . .] (b) attached to offices and positions open to all under conditions of equality of opportunity'). A globalised version of (b) would entail that two individuals living in two different countries that are unequally developed should have the 
same chances of succeeding in life, net of differences in individual abilities. ${ }^{1}$ In other words, the principle of global equality of opportunity would regard as unacceptable that a child born in Gambia and who has excellent educational achievements has much less chance of occupying a prominent position in either multinational companies, or international organisations, or international law firms than a child born in Vienna with just above-average educational achievements (see also Moellendorf 2002, p. 79).

It is important to note that the principle of equality of opportunity and the difference principle, which Rawls combines at the national level posing the former as lexicographically superordinate with respect to the latter, are not necessarily in a chain of mutual realisability. As an example, consider the case in which the child born in Vienna, grown up, retains a consistent margin of life opportunities over the other individual born in Gambia, but he takes part in a global mechanism of wealth distribution that fuels resources to his Gambian counterparts as long as he makes career progressions. In this situation, a global difference principle might be met, while the principle of global equality of opportunity would not. Accordingly, many theorists insist on the difference principle, while reasoning on global justice, because it is much easier to be implemented, through global funds and development agencies that allocate the resources on local territories, for example.

At the same time, this distribution of resources would also contribute to reducing global inequality of opportunities, because it would grant the worst off more resources to compete with the best off. Yet, a comprehensive implementation of global equality of opportunity would require a much more complicated programme of reform and homologation of both schooling and recruiting practices that, admittedly, risks sounding utopian, at least for the moment. Much more realistic, in its chances of implementation, is the interpretation of the global original position given by Gillian Brock (2009), according to whom the output of the global social contract would not be a sort of global egalitarianism, as postulated by her cosmopolitan colleagues, but rather a set of principles that look at absolutes, instead of relativities. Thus, Brock defends a global floor as a demand of global justice, that is to say, an agreement on a capability threshold below which no one should be allowed to fall.

\section{NON-RELATIONAL THEORIES OF GLOBAL JUSTICE}

Non-relational theories of justice ground distributive duties on factors that are intrinsically human and pertain neither to interactions nor to the creation of 
a cooperative surplus; this is why they can be defined as practice-independent. This makes it almost obvious that these theories should be applied globally. The only thing required is to recognise a kind of anthropological and biological equality between human beings. There are two main strands of non-relational theories of justice. The first one takes the individual as an agent of value maximisation, where value can be either understood as realised well-being, as preference satisfaction, or as happiness, and it can be either taken in its absolute value or pondered over factors that are inversely proportional to well-being or subject to one or more thresholds. In sum, I am referring to utilitarianism, prioritarianism and sufficientarianism - at least in its classic formulations (Mulgan 2007; Holtug 2007, 2015; Shields 2016; Corvino 2019b). The second strand is centred on human needs, and more generally on an Aristotelian-like belief that humans depend on society to lead 'flourishing' lives; hence society as a whole bears a responsibility towards its single components to provide them with the opportunity to achieve the things they might want to be or to have. Here the reference goes obviously to the capability approach (Nussbaum 2006, 2011; see also Robeyns 2016), but also to the more recent formulations of capabilitarian sufficiency (Nielsen and Axelsen 2017), which somehow oscillate between the first and the second strands of practice-independent theories.

The basic tenet of utilitarianism is that every human being can experience gains and losses of utility and the moral imperative, to which both individuals and institutions should adhere, is to ensure that general utility is increased as much as possible. Then, utilitarian philosophers disagree about what utility consists of and whether the imperative of utility maximisation applies to single actions or to a set of rules. For some, utility is realised happiness or satisfaction, for others it is the realisation of either preferences or desires, for still others it consists in the fulfilment of an objective list of human needs, or more specifically in perfecting human nature (Mulgan 2007, pp. 61-92; Crisp 2017).

Moreover, some people believe that it would be right to take an action which violates some rules that overall maximise utility, on condition that this action brings about a positive balance of lost and gained utility regarding its direct consequences. Imagine, for example, that you are late for an important appointment, you are driving, and you come up to a red light. A so-called 'act utilitarian' might say that if you are sufficiently sure that no one is passing by, no one is watching you, and the person waiting for you is suffering a loss of well-being for every minute he is kept waiting, you might be justified in proceeding without waiting for the green light. Conversely, even under such circumstances, a 'rule utilitarian' might object that the right action to take is not the one that maximises utility in itself, but rather the one that conforms to the rule increasing overall utility, in this case respecting red lights (see also Emmons 1973). 
Nevertheless, even though utilitarians are usually criticised by egalitarians because they look at aggregate utility while considering the equality in distribution only of derivative importance, ${ }^{2}$ it is important to recognise that there is a sort of 'hidden egalitariansm' in the utility function, meaning that a given unit of utility matters the same, from a moral point of view, regardless of the person who produces it and of her social position (Sen 1992, p. 13). Paradoxically, it is exactly this egalitarianism of utility functions that paves the way to outweighing mechanisms between the best off and the worst off, and more generally to adaptive preferences. Accordingly, a middle-class person living in a developed country could have very limited distribution duties towards an individual living in a poorer country if the former experiences strong frustrations and the latter has adapted to live in her situation of deprivation, or maybe she has not had the opportunity to imagine a different life. This is why prioritarian philosophers have postulated that the absolute value of each unit of utility should be pondered over a number that reflects the welfare level of the person that realises utility - the higher the welfare level, the lower the pondering factor. In this way, trade-offs between the top and the bottom of societies, due to the discomfort of those who are in the former group and/or the adaptive preferences of those who are in the latter group, are severely restricted (see also Corvino 2019b, pp. 525-36).

Again, another possibility for correcting for the unequal drifts ignited by the egalitarianism of utility functions, in addition to and/or in the place of the prioritarian amendment, consists in holding that well-being matters, in the moral calculus about justice, only above a given sufficiency threshold. Accordingly, justice would require leading any individual above the sufficiency threshold and any inequality that occurs above the threshold is irrelevant from the point of view of justice in distribution. The clear advantage of sufficientarianism with respect to both utilitarianism and prioritarianism, from the perspective of the worst off, is that it resolutely excludes any trade-off between the top and the bottom, while the limit is that it gives up on every aspect of redistributive leverage among those who are sufficiently well off (Casal 2007).

Not every sufficientarian thinker is a repentant utilitarian. Instead, many sufficientarians have developed their theories as an alternative to telic egalitarianism, arguing that what is intrinsically valuable is not equality but everyone having enough of something, or even adding that equality per se is a dangerous

2 In many cases, rendering a distribution of goods more equal increases overall utility because of the law of decreasing marginal utility, so in this sense we might say that equality can be instrumental for utilitarians to implement their moral imperative. Just think how a global redistribution of wealth might move resources from people who get a low utility from them - because they are rich - to other people who might get much higher levels of utility - because they are poorer (see Singer 1972). 
normative objective because it leads to 'moral disorientation and shallowness' and deflects attention from 'considerations of greater moral importance' (Frankfurt 1987, p. 23). It is difficult to generalise on the nature of sufficientarianism, given that some thinkers limit their attention to the importance of the sufficiency thresholds (Shields 2012; Axelsen and Nielsen 2015), while others combine it with forms of either prioritarianism or utilitarianism both above and beyond sufficiency (Crisp 2003; Huseby 2010). Rather, what it is important to stress here is that the simple idea at the basis of sufficientarianism is either based on the revised conception of the individual as a subject who can experience gains and losses of utility and be an engine of its maximisation in the world, or as an alternative view to the one that equality is important per se and hence we should strive, normatively, for a more equal distribution of resources. In both cases, as also for utilitarianism and prioritarianism, the normative provisos are disentangled from the social relations that subsist among the members of the distributive scheme. Looking at the issue from another perspective, we may say that it does not really matter for utilitarians, prioritarians or sufficientarians how far off the individual who could best serve the normative objective is - be it to maximise utility, to maximise the value of pondered utilities, or to minimise the number of people who live below sufficiency - if she is assigned the right resources.

The second main strand of non-relational theories of justice is the capability approach, in the normative formulation initially given by Martha Nussbaum (2000, 2006, 2011), and in parallel with the treatment of capabilities as measures of well-being that Amartya Sen $(1992,1999)$ made in the course of the last decades. Nussbaum's basic intuition, from where her whole theory unravels, is that some specific human abilities 'exert a moral claim that they should be developed' (Nussbaum 2000, p. 83). This is a moral idea that stems from the very empirical fact that human beings have special needs that require special 'nourishment' (see also Nussbaum 1995). When the latter is denied, and these needs remain unfulfilled, human beings lose the ability to flourish. The main difference between humans and animals, then, lies in the percentage of external intervention that they respectively need to flourish. An animal, in general, only needs life and some assistance during the first years of life. A human being needs much more, from education to health care, recognition, freedom of expression, and so on.

There are three kinds of human capabilities. Firstly, 'basic capabilities', those that do not need particular external intervention to start functioning. For example, the capability for speech is developed by the child almost automatically when she is raised in a normal context, with other human beings. In this respect, speech differs from writing skills. Secondly, there are 'internal capabilities' that require the individual to reach a mature condition of readiness before she can start making them function. The capability for sexual pleasure, 
for example, is developed without any support once the individual reaches a given age. Lastly, there are 'combined capabilities', that is to say internal capabilities that need to be combined with 'external conditions for the exercise of the function'. Nussbaum offers the example of a woman who automatically develops the capability for sexual pleasure at a given point of her life, and for her to enjoy this capability she only needs that other people abstain from odious practices such as genital mutilation. At the same time, for the 'internal' capability for sexual pleasure to evolve into the 'combined' capability for sexual expression, it also takes social circumstances to be arranged in a way to guarantee this capability - e.g. widows should be allowed to marry again and girls should not be discriminated against or penalised for engaging in relations before marriage (Nussbaum 2000, pp. 84-5).

Therefore, combined capabilities are those that an individual can realise when two conditions hold. First, the social organisation does not interfere with the development of the internal capability. Second, the social organisation 'prepar[es] the environment' for the internal capability to evolve into a combined capability (Nussbaum 2000, p. 85). Here we get to the basis of the moral argument put forward by Nussbaum. Since we cannot expect human beings to develop combined capabilities on their own, and the enjoyment of a basic set of 'combined capabilities' is a fundamental prerequisite for a flourishing life lived with dignity, every human being exerts a moral claim to be provided with the necessary means to develop this basic set, and the correlative duty falls upon humanity as a whole.

As we can immediately see, Nussbaum's approach to justice is non-relational. ${ }^{3}$ Human needs do not presuppose interactions to arise, rather they pose the demand of creating social interconnections when they are lacking and are needed to allow a certain group of individuals realising a basic set of combined capabilities. This is why the capability approach is in itself a cosmopolitan theory, which, differently from classic forms of contractualism, manages to take into account ex ante the interests of those individuals who are prevented by bodily or cognitive obstacles to relate as equals to the rest of society. Conversely, the drawback of a non-relational account of justice that moves from needs, in comparison, for example, with contractualism, is that it takes much more in terms of ethical justifications to explain why individual limits, intrinsic to human beings, command contribution by other members of society even in the absence of a cooperative surplus. And obviously, it is much more

3 At least as far as the minimum for conducting a decent life is concerned, given that Nussbaum does not exclude that her theory can be complemented with more encompassing theories of justice. See Nussbaum 2006, pp. 22-5. 
complex to explain how the responsibility of society towards the individual unfolds between its individual members.

\section{THE INJUSTICE THAT BOTH RELATIONAL AND NON-RELATIONAL THEORIES FAIL TO CAPTURE}

Theories of global justice, be they relational or non-relational, are founded on the premise that the current global distribution of resources should be changed because of the consequences it triggers rather than because of the way it originated. So, global egalitarians criticise global inequality because it falls short of the optimal arrangement that free individuals would agree upon in a hypothetical session of the global contract. Utilitarians recommend that the rich should give a considerable part of their wealth to the poor because the latter would yield greater utility from it. Prioritarians propose a similar argument, although they are interested in 'compound states of affairs' (Holtug 2007, p. 132), that is to say pondered value, rather than simple utility. Sufficientarians insist on the axiological argument that a world in which $n+1$ people have enough is better than an alternative world in which only $n$ people have enough. The capability approach maintains that every human being exerts a moral claim to live a life with dignity, and that a global redistribution of resources could accomplish this goal.

All these theories fail to sanction the forms of injustice that are inherent to the capitalist mode of production, which is the common social system through which individuals yield the wealth that global justice theories consider as 'unjustly' allocated throughout the world. The main one is that the vast majority of people taking part in jointly productive practices are compelled to do so for the lack of viable alternatives. Accordingly, there are two normative problems with the unequal distribution of resources in the world. The first one is that wealth is produced in a condition of systemic unfreedom. The second one is that after it has been produced, wealth is distributed in a way that is normatively unsatisfactory, be it because the distribution is unfair, or falls short of maximising utility or value, or because it prevents some individuals from fulfilling a basic set of combined capabilities, and so on. Obviously, the two problems are intertwined, because the more unequal - or also the less performing in maximising utility or value - a given distributional scheme is, the greater the barriers that keep people stuck in a market relation. And vice versa, the more access people have to the means of production, the more possibilities there are to arrive at a fair distribution of the wealth produced. Yet, the two problems remain distinct and should be addressed in a different way (see also Forst 2001, pp. 167-70; Laborde 2010, pp. 49-53; Buckinx et al. 2015).

Both relational and non-relational theories of justice are well fitted to deal with the second problem concerning wealth distribution, but they lack 
the necessary theoretical tools to properly address the first problem. For an individual who has an improvement in well-being from time $t$ to time $t 1$ could experience in the same time period $t-t 1$ a greater commodification of her work. In other words, she may find herself with more resources at her disposal but less freedom than before. The reason why this trade-off between well-being and freedom is usually overlooked in the discourse on socio-economic justice is that the trade-off only takes place as long as the welfare gains start from a low level and are contained. If in the transition from $t$ to $t 2$ (subsequent to t1) the increase in well-being resulting from wage work is substantial, then the individual could set aside a sufficient amount of resources to guarantee for herself a level of independence from market relations equal to or greater than she had at the time t. Conversely, when we consider the situation of a person who experiences a slight increase in well-being, shifting, for example, from relative poverty to just above the line of relative poverty, it might be the case that this improvement in well-being has occurred at the price of labour commodification - and an example might be a person who is contracted to work the land that she used to cultivate for free before, and, thanks to the productive investments of the land grabber, she is paid a wage that is higher than the income she managed to get before as a self-producer (see Cotula et al. 2009). This poses a double problem, as already hinted at earlier. A loss in individual autonomy raises a normative issue per se, meaning that either it is justifiable or it is arbitrary and hence unjust. Moreover, as a result of the trade-off between well-being and freedom, at time $t 1$ the individual may be better off in terms of income but more exploitable than at time $t$, meaning that the loss of the opportunity to obtain a minimum income from self-employment reduces the individual's margin of discretion over the offers of those who control the means of production.

\section{NEITHER FUNCTIONAL, NOR ETHICAL, BUT A MORAL CRITICISM OF CAPITALISM}

Assuming that I have provided sufficient reasons to justify the difference between classic approaches to global justice and the one based on capitalist structural domination, at least enough to convince the reader that it can be worth going through the following pages and to test the soundness of the general argument, there are two other preliminary points that I should address. I have to demonstrate that mine is neither an attempt to re-present in a new guise the classic arguments against capitalistic society, on which 'critical theorists' have written so much, nor a nostalgic exaltation of an Arcadian pre-capitalist society.

I start with the first issue. In a quite recent but already seminal article, Rahel Jaeggi (2016) tackles the question whether we can say there is something 
intrinsically wrong in capitalism, which was famously posed in these terms some years before by Philippe Van Parijs (1984) in another article. When we speak of something 'intrinsically' wrong with capitalism we refer to something wrong that we could not have under different social arrangements (Van Parijs 1984, pp. 85-6). So, for example, neither by saying that the spread of smartphones is regrettable because it puts social relations at risk, nor by complaining that human beings are led to put their own gain before everything else, nor by denouncing that metalworking industries are an imminent danger because of their contribution to climate change, would we be making an argument against capitalism in itself. In fact, beyond the question of whether they are more or less true, the first and third points pertain to the contemporary condition, and they might hold true as well under different modes of production. A socialist society, just to mention one possible alternative, would not necessarily undertake a green transition, and nothing excludes that even if private property were nationalised, public industries would keep on producing and commercialising smartphones, which in turn are connected via public Wi-Fi. The second point, concerning human egoism, is a descriptive assertion on human beings in general, and could not even be considered as a proper criticism against an intrinsic feature of capitalism, because the origins of the problem substantially transcend its boundaries.

Accordingly, Jaeggi (2016, p. 47) maintains that there are three possible levels on which to criticise elements intrinsic to capitalism. The first level is functional and pertains to the capacity of the capitalist system to fulfil its purpose. Here, everything depends on what we mean by the purpose of capitalism. If we stick to a morally neutral view, we would have to say that capitalism can at a certain point become dysfunctional if it ceases to create marginal increase in wealth, thus making society progressively worse off in aggregate terms, or if it undertakes a self-destructive process (Jaeggi 2016, pp. 47-53). Both criticisms are misplaced at the moment, given that in spite of recurrent crises, global gross domestic product (GDP) keeps on growing every year, capitalism has proved to be quite resilient, and because there are no implementable alternatives in sight, at least for now. It might be said that capitalism is dysfunctional because climate change poses serious threats to humans and non-human animals (Hannah 2019; McDuff 2019). But some people would reply to this by saying that within capitalism we could obtain a win-win solution, in terms of both sustainability and economic growth, through a sort of Green New Deal aimed at financing the green transition (Klein 2019; A. Turner 2019). If this were true, phenomena such as life-threatening CO2 accumulation could not be taken as intrinsic features of capitalism - since we can conceive the latter without the former.

A seemingly functional argument against capitalism, which is both empirically grounded and which targets its intrinsic features, could be that capitalism 
is bad because it leads to global inequality and/or to massive poverty. Let us assume that that empirical causality is sound, even though recent economic trends might show something different (Milanovic 2016), but I will come back to this in a while. The problem with this kind of objection, as rightly noted by Jaeggi (2016, pp. 49-53), is that it cannot prescind from some moral premises, or in other words from value-laden functions that we assign to capitalism. By saying that capitalism is falling short of a normatively desirable distribution, we automatically assume that this distribution is part of capitalism's functions, which is something we cannot infer from a morally neutral interpretation of the purpose of capitalism - that is to say, as a mode of producing wealth. Consider the example of the knife made by Jaeggi (2016, pp. 48-9), whose function, she says, is clearly to cut. We might elaborate a little further on the knife and hold that it can either be used to harm someone just for the sake of causing him pain, or to go to the aid of other people, as when it is held against a terrorist in the attempt to stop him.

We might speculate on whether in each of the two cases the knife has been used to determine good or bad results, or even on whether its same use can be justified, but these kinds of speculations, which pertain specifically to its use, have nothing to do with its function, which remains, simply, to cut. In the same way, we can propose different normative evaluations concerning the use people make of the wealth yielded by capitalism, and of the way they distribute it, but these would not reach the function of capitalism, which is to guarantee a more or less constant rate of growth. More specifically, these normative evaluations are the ones that lie at the core of theories of global justice (or justice in general) which are doomed, because of the value judgements that precede them, to stop before the functional level, at the moral one. Moreover, as already noted, classic theories of distributive justice are very good for proposing a normative critique of the process of wealth distribution but not as much for criticising the human condition in the process of wealth production - even when coupling positive with negative duties of justice, but I will focus on this in the next section.

A moral critique that focuses on wealth production instead of distribution is the one which holds that there is something wrong in the way those who control capital relate to their employees; namely, the former exploit the latter (Jaeggi 2016, pp. 53-60). The idea of exploitation, together with that of domination, will be at the centre of Chapter 2. However, here we might say, quite generally, that an individual A exploits an individual B when the former gives the latter less than the fair amount of something, and usually in job contracts we focus on wages. The theoretical challenge consists in explaining what a fair remuneration is all about (see also Arneson 1981; Roemer 1985; Vrousalis 2013). As we shall see in Chapter 1, a first articulate response to this question was given by Karl Marx (2013 [1867]). In a nutshell, his theory of exploitation 
proceeds in two stages. First, a group of individuals deprives another group of individuals of access to the means of production, with an active role played by modern states in promulgating laws that enclose common property. Second, newly formed capitalists extract so-called 'surplus value' from workers by paying them less than the value they convey to the objects they work on. Both steps of Marx's theory have been criticised over the years, and more specifically what is called into question is the relevance, nowadays, of the concepts of 'primitive accumulation' and 'surplus value'. We shall have time to deal with both issues later on, but merely to defend the relevance, at least under specific circumstances, of Marx's theory today, I shall point to four well-known facts. Firstly, thousands of people living in developing countries keep on losing their means of subsistence because of land grabbing, that is to say because the land on which they rely for sustenance is sold by their countries to foreign investors. Secondly, millions of people, especially young people, throughout the world are paid a wage that is barely sufficient to put a roof over their heads and perform minimum social and biological functions - namely, eating, being decently dressed and if they are lucky having dinner or a couple of drinks with friends during the week - while offering their employers, be they private or public, a work performance that allows the raising of much higher profits than the welfare they enjoy. In many other cases, young workers are even asked and encouraged to work for free, to enrich their $\mathrm{CV}$, that is to say to obtain the minimum requirements necessary to enter, as passive subjects, into the circuit of surplus-value extraction. Thirdly, thousands of people living in developing countries work for a few dollars per hour on semi-laboured products which are then sold on the global market at astronomic prices. Fourthly, even those workers who manage to get good wages in sectors where technologies progressively increase labour productivity are, in fact, only getting back a small part of the value they produce, while the largest part of this value turns into profits.

The third level of intrinsic criticism of capitalism is instead ethical. This critique contends that the problem about capitalism is that it negatively impacts on the human condition in a way that other forms of production would not do. As an example, it might be held that capitalism erodes cultural differences by promoting a kind of fast-food and cheap-garment homologation - and, obviously, a hypothetical proponent of this argument would have to explain why fast foods and the fact that millions of people wear the same cheap clothes are ethically bad. Or it might be said, as did the young Marx (1988 [1844], pp. 69-84), that wage work, which is a defining feature of capitalism, alienates individuals from the object they produce, within the productive process, in relation to other individuals and with respect to their existential purpose. Jaeggi $(2015,2018)$ further develops this line of argument and maintains that we could (and should) criticise capitalism as 'a form of life', that is to say as 'a bundle of social practices' that subvert the true ethical significance of 
human life. And the main ethical problem on which she focuses her critique is alienation, the social phenomenon through which human beings lose control of their actions and consequently suffer a loss of meaning in relation to the world around them. All this poses a relevant ethical problem because it distances the human being from her own social existence, while the two entities are ontologically intertwined (Jaeggi 2014). In short, we could summarise Jaeggi's normative argument as an ethical complaint about the 'detachment or separation from something that in fact belongs together, the loss of a connection between two things that nevertheless stand in relation to one another' (Jaeggi 2014, p. 25).

My argument in this book is neither functional, nor ethical. It is a moral one, yet differently from classic moral critiques of capitalism, it maintains that the normative problem does not reside in interactional relations on the market place - e.g. exploitation by employers over employees - but is rather systemic and pertains to the distribution of the means of production and to the extreme levels of labour commodification that it brings about. More specifically, my critique is not functional insofar as I assume that for the purpose of creating well-being and enlarging individual capabilities, capitalism is the best mode of production with which humans have ever experimented. I recognise, obviously, that huge distributive problems have existed throughout the history of capitalism and continue to exist today, although in a different form, but I hold that these problems are not intrinsic to capitalism, given that they can be reverted through regulations, and the fact that globalisation makes global cooperation for redistributive purposes very difficult is not a direct consequence of capitalism. I hold the same about environmental problems related to climate change. More specifically, I embrace the view that it is possible - and even desirable - to disentangle economic growth from unsustainable emissions, through right investments and more public control of the economy. Another viable position that I can accept without upsetting the structure of my argument is that the only possible way to save our planet is to renounce economic growth, which does not necessarily account to a rejection of capitalism in itself, given that it could also be possible to imagine a capitalist society that voluntarily chooses to renounce the increase of growth rates. Here we are moving on speculative grounds; hence what I can do from a normative point of view is to accept the economic forecast that seems to me more reasonable in the light of the literature I have gone through in the last years. Yet, should my position be empirically wrong, because in the future we may find out that capitalism is structurally incompatible with human preservation, there are two possible ways to accommodate this new empirical evidence in my critique of capitalism. If capitalism continues to exist, in spite of the fact the humans will be sure that it is functionally detrimental, the moral argument I shall propose in the next pages can be read in parallel with the functional critiques that I am 
sure future theorists will provide in a refined way. If, instead, capitalism is superseded, the arguments that lie behind the minimum de-commodification of labour power can be read in a historical perspective as a normative critique of the social system that has characterised an important stage of human civilisation.

Moreover, when dealing with labour commodification I shall leave aside ethical considerations of a cultural character, and consider the phenomenon of alienation as of normative derivative importance with respect to the distribution of the means of production. If I have to be more accurate, I remain agnostic about the critiques that revolve around the way we live and the consumer choice we make within capitalism, not because I disagree with many of these claims, but because I consider them as less stringent, from a normative point of view, than a moral and political argument based on individual freedom. Moreover, cultural criticisms of capitalism are subject to trade-off counter-objections of this kind: would you prefer to eat cheeseburgers in a fast-food restaurant that contaminates the artistic beauty of Piazza del Duomo in Milan or to starve in the middle of a medieval famine? I would opt for the former. My position with regard to alienation is more complex, however. I recognise the urgency of the issue, which I shall also discuss later, yet a purely ethical treatment of alienation makes sense, in my view, only if the moral level of critique is not practicable. This is the position taken, for example, by Jaeggi. She provides many arguments as to why both the functional and the moral levels of critique could be inconclusive and falls back on an elegant ethical theory. I agree that alienation is a huge ethical problem, yet I also believe that there is room for a moral and political critique of capitalism. Hence, I shall argue that alienation is a problem, first of all, as a consequence of the fact that a large group of human beings can only seek basic sustenance in wage income, which in turn accounts for structural domination.

In sum, this book is positioned on the moral level of critique of capitalism, with important political corollaries stemming from the moral premise based on the preservation of individual autonomy. I maintain that some intrinsic features of capitalism, namely the privatisation of the means of production and the consequent commodification of labour, cause many individuals to lose their freedom. Yet, I shall contend that within capitalism freedom is lost neither in the marketplace, at the moment when capitalists meet commodified wage-workers and impose obnoxious conditions, nor at the workplace, where capitalists can force the limits of what has been agreed during the bargaining phase of the contract. I shall hold, instead, that within the capitalist social system many individuals lose their freedom, for systemic reasons related to the privatisation and the distribution of the means of production, long before they enter the market. Usually it is a condition that accompanies the individual from her birth. Accordingly, I argue that what then occurs on the market is a matter 
of exploitation, which is of course morally reproachable, but does not account for capitalist domination. The latter is only systemic.

There are several advantages in adopting a structural approach to capitalist domination. First, the scope of responsibility for domination is substantially extended, in comparison with a purely interactional approach, to those who more or less directly support the current division of the means of production. Second, despite the fact that responsibility for domination of wage-workers is politically dispersed, the employers who profit from the asymmetries of power with employees (created by structural domination) to exploit them, remain morally blameworthy of exploitation. In this sense, exploitative employers carry a double responsibility: a political responsibility for domination of wage-workers (shared with a large group of people) and moral responsibility for their exploitation. Third, from the political perspective that I am outlining, the concept of exploitation is reduced to the minimal moral premise: human beings shall be free from domination. In other words, I will not hold that individual A exploits individual B because A offers B less than it would be fair to give her in return for her work performance, where 'fair' may refer either to a wage that includes the value that the worker transfers to the object of production in terms of work effort, or to a wage that is not disproportionately lower than the marginal increases of profits that the employer obtains thanks to the work performance she hires - two parameters that would require the previous acceptance of thicker moral premises, that is to say, either that wages should somehow embody work hours, or that profits should be distributed more or less equally among all the individuals that contribute to yield them. I shall contend, instead, that A exploits B insofar as A offers B a remuneration that is lower than B would have accepted had she not been in a condition of systemic domination, that is to say, had she had other valid alternatives to seeking sustenance in a market relation.

\section{NEGATIVE DUTIES OF JUSTICE}

Theories of justice normally include both a positive and a negative component. The positive component of a theory of justice is that for which a given individual (or group of individuals) has a series of duties to do determined things for the benefit of another individual (or group of individuals). So we may say, for example, that among all the members of a social group who receive an income there exists a positive duty to pay taxes, according to schemes that can be more or less progressive. And as we have seen before, this positive duty can be either practice-dependent (e.g. for contractualists) or practice-independent (e.g. for utilitarians, prioritarians or sufficientarians). Usually, every theory of justice that prescribes certain positive duties recognises the existence of parallel negative duties. The most uncontested of the latter is that you should 
not cause avoidable harm to others; and if you do so, you need to provide compensation. Some theorists have adopted a negative approach to global justice. They have postulated that wealthy individuals owe a redistribution of wealth to poor foreigners as a matter of redress for having caused them harm, or more generally for having violated one or more of their rights. There are two main theoretical reasons for taking this stand. The first one consists in globalising a theory of justice that is merely focused on property rights; the second one is to bite the bullet of statist thinkers concerning the domestic scope of positive duties of justice while arguing that, even if their counter-objection were true, the unquestionable duty not to cause avoidable harm to others would justify the provision of compensation to the world's poor.

The first is the case of left-libertarians, who argue that wealthy individuals owe a redistribution to the world's poor for having appropriated more than their equal share of the world's natural resources. More generally, left-libertarians share with right-libertarians - whose most famous contemporary exponent is Robert Nozick (1974) - the belief that all individual rights, including property rights, stem from individual full self-ownership. Every individual owns herself, as she might hold an external object, insofar as she retains 'full control rights' over her intellectual faculties and her body, 'full rights to transfer' the control rights - e.g. by signing a job contract or offering the performance of a service to a friend - and 'full payment immunities' for the possession of control rights (Vallentyne 2000, pp. 2-5). The latter point is the trickiest and marks the difference between libertarianism (both left and right) and the various forms of egalitariansim, because it implies that those who manage to accumulate great wealth through just transactions, that is to say, transactions that do not violate justice in acquisition, cannot be asked to renounce even a small share of this wealth by virtue of what Robert Nozick (1974, p. 156) defined as 'patterned' principles of justice. Then, left- and right-libertarians disagree on how human beings come to own external objects, and in particular natural resources. Right-libertarians follow John Locke in contending that natural resources are originally unowned and human beings acquire property rights over them by applying their own work on them (Nozick 1974, pp. 174-82; see also Otsuka 1998). Conversely, left-libertarians postulate that natural resources are equally owned at the origin. Thus, from this normative premise they rightly infer that the extreme forms of poverty and inequality are unjust, because they violate the original just distribution of natural resources; hence compensation is owed by over-appropriators to under-appropriators (Steiner 1994, pp. 266-82; 2009).

I think it is useful to enter into even more detail at this point, because the libertarian theory of just acquisition of natural resources will become central in outlining the contours of MDL. Right-libertarians usually recognise the validity of the so-called Lockean proviso, according to which a given individual can appropriate a natural resource as long as she leaves 'enough, and as good 
left' (Locke 2003 [1689], ch. 5, para. 33, p. 114). As Nozick (1974, pp. 175-8) has rightly stressed, there is both a 'stringent' and a 'weaker' interpretation of the basic idea of the proviso, namely that any individual appropriation should make others worse off. The 'stringent' interpretation would be extremely challenging for right-libertarianism, because it would oblige it to a subsistent restorative redistribution. In fact, the 'stringent' interpretation would imply that one individual makes another worse off either by preventing her from being better off tout court or by subtracting from her what she was previously free to use. Conversely, the weaker interpretation implies that one individual can make another worse off through an appropriation only in the first sense of the stringent interpretation.

The normative consequences of the two interpretations are fundamental. The stringent interpretation would imply that there can be no trade-off between access to natural resources, on the one hand, and the widespread advantages of modern economic growth sparked off by capitalism, on the other. Accordingly, even if we assume that everyone is better off within capitalism, the denied access to natural resources makes a large group of individuals in some respects worse off than if there had been no private appropriation of natural resources. Thus, those who control nature-based means of production, such as land, would owe compensation to commodified individuals, regardless of how good the latter are all things considered. Nonetheless, right-libertarians, including Nozick, usually avoid this radical conclusion by inclining towards a weaker interpretation of the Lockean proviso. They maintain that even though the private appropriation of natural resources has prevented many individuals from using some specific objects, this has not prevented them from improving their conditions, for example getting hired by those who control the means of production. In other words, right-libertarians appeal to trade-offs between wage-money and direct access to natural resources, holding that within capitalism the former can tremendously counterbalance the latter. Moreover, libertarians might even go further and contend that the establishment of private property has made even those who do not receive job offers better off, because it is implied - in a fairly questionable way, honestly speaking - that the means of production will end up in the hands of those who can use them in the most efficient way, so as to take entrepreneurial risks and increase social well-being (see Nozick 1974, p. 177). Hence, it might be postulated that a currently unemployed and subsidised person is better off than she would have been in a pre-capitalist society in which she had access to a small share of natural resources. And as we can see, these possible declinations of the weaker interpretation of the Lockean proviso minimise the space for wealth distribution.

On the other hand, left-libertarians are able to move a more imposing redistributive lever because, unlike right-libertarians, they do not postulate that natural resources are originally up for grabs - although conditioned to a more 
or less stringent interpretation of a Lockean proviso - but are equally owned by all human beings. Then, left-libertarians are divided over what an equal ownership of natural resources entails. A first view is that natural resources can be privatised upon collective consent, and obviously here the challenge consists in explaining how this consent can be given without incurring unsustainable administrative costs. The second view is that natural resources should remain equally owned; hence individuals can only use them temporarily - as when you go for a picnic in a public park - but clearly it is extremely difficult to imagine how this scheme might work in a society that has reached the current level of technological development. Lastly, the most implementable view of equal ownership is that natural resources can be unilaterally seized, on condition that the 'competitive value' of the natural resources taken from the common pool is paid for. This is the view adopted by Georgist libertarians, who owe their name to the nineteenth-century American political economist Henry George and who have among the most important contemporary representatives Hillel Steiner and Nicolaus Tideman (see Vallentyne 2000, pp. 5-10; see also Vallentyne and Steiner 2000).

More specifically, the competitive value of natural resources is best understood as a rent rather than a full appropriation, given that we should never lose sight of the fact that future generations will advance legitimate claims on initial joint ownership. The payment of the competitive value should not be confused with what Peter Vallentyne (2000, p. 9) calls 'full-benefit taxation'. Let us imagine that both individuals A and B seize 100 sq. m of land each; the competitive value of 100 sq. $\mathrm{m}$ of land is 40 coins and the initial egalitarian ownership of natural resources entitles every person to control resources only up to the value of 10 coins. Let us also add that $\mathrm{A}$ is more talented and industrious than B, so she manages to get 80 coins per year from her land, while B only gets 60 coins. According to Georgist libertarians, both A and B have to give away the same amount of coins, namely 30 coins per year (40 minus 10$)$, while according to purely egalitarian accounts - that embody a more or less encompassing conception of full-benefit taxation - A and B should be charged differently, for they should also be taxed on the coins that they yield net of the competitive rent of their land, respectively 40 coins (80 minus 40) and 20 coins (60 minus 40).

As we can see, Georgist libertarians are in a certain sense 'more egalitarian' than right-libertarians, but as their right-colleagues, they fall short of justifying a taxation of income differentials stemming from individual efforts and also to compensate for cases of brute luck, that is to say, for either market or individual failures that cannot be avoided. Yet, a theoretical attempt to make left-libertarianism converge on more egalitarian policies, while not renouncing self-ownership and the assumption that distributive justice is limited to restoring justice in acquisition, is the normative treatment that Hillel Steiner 
(1994, pp. 274-80; 2002; 2009) makes of genetic endowments. He postulates that any achievement an individual obtains in life is the result of three different elements (in addition, obviously, to social and natural contingencies that limit individual agency): genetic endowments, individual efforts in developing personal talents and the social output by parents in raising their children. From a libertarian perspective, it would be unjust to tax the individual for the share of her achievements that are imputable to the last two factors, which are in turn attributable to individual self-ownership (either of the individual herself or of her parents). Yet, genetic endowments are a sort of natural resource that parents mix in conceiving their children and that pre-exist them; hence they are excluded from self-ownership. Cutting a long story short, Steiner maintains that those parents who 'use' a genetic heritage of above-average quality have to pay a tax to a global fund, exactly as those over-appropriators of other natural resources are expected to do.

Keeping aside the way Hillel Steiner seeks to level out the social advantages stemming from different individual talents without recurring to 'patterned' principles of justice, and focusing exclusively on property rights, left-libertarians tackle the problem of the unequal division of the means of production, at least of its natural component, and like the MDL proposal I shall advance in this book, they do not claim that the initial equal ownership should be restored; rather, they accept that private property has made society substantially better off in a diachronic sense - and on this they agree with right-libertarians. Nonetheless, there are two important differences between left-libertariansim and MDL that I hope will become clearer in the next chapters, but which can - and should - be briefly summed up here. First, left-libertarians are bound to a very thick normative premise, namely that natural resources are initially jointly owned; whereas MDL only postulates that individual autonomy is inviolable. Many philosophers, and in general many people, would resist the former claim, but very few would oppose the latter. Second, nothing rules out the possibility that a person who has been compensated for the violation of her property rights over natural resources ends up back in a condition of extreme labour commodification, that is to say, she can exhaust her compensation and be compelled to enter into a market relation, and this could happen either because she has mismanaged the resources she received from the left-libertarian fund or because of contingencies that were out of her control. If that occurs, left-libertarianism would be unable to justify any social intervention aimed at guaranteeing her a decent life outside the market. In this sense, we may say that left-libertarianism is simply concerned with property rights while MDL takes as its point of reference the human condition per se, in respect to which property rights may be instrumental in ensuring autonomy - a basic precondition for the human condition to be decent - but they do not represent the necessary point of departure. 
Another, different use of the concept of negative duties of justice, in a global context, is the one shown more recently by Thomas Pogge (2008). Instead of taking as a cue the duty to not violate the property of others - which, as we have seen, requires a previous assumption about what a just distribution of property originally is - he focuses on the much less questionable concept that it is wrong to cause harm to someone else when this can be avoided without incurring unsustainable costs. Accordingly, he justifies a global distribution of wealth on the grounds that people living in developing countries are giving their democratic support to governments that in turn keep a global order in place which causes avoidable human rights deficits to the world's poor (Pogge 2008, pp. 18-32). Hence, the former owe compensation to the latter, which can take the form both of efforts to reform the global order and transfer of resources to the victims of injustice (Pogge 2008, pp. 202-21). It is important to point out, as indeed it is pressing to do to the same Pogge, that the notion of harm he employs for the global realm is quite restrictive, in the sense that A harms B as long as A - more or less directly - causes a violation of B's human rights, but $\mathrm{A}$ does not harm $\mathrm{B}$ for the sole reason of providing $\mathrm{B}$ with a treatment that is less than optimal. Let us consider, as an example, the case in which A and $\mathrm{B}$ are respectively the governments of a developed and a developing country bargaining over the terms of bilateral trade agreements. Let us also assume that A leverages its greater economic power to reap an agreement that disproportionately benefits its farmers to the detriment of B's farmers. From Pogge's perspective, we might say that the government of country A - and indirectly those citizens who have elected it or have not taken a clear stance against it are harming the farmers of country B only on condition that human rights deficits - such as cases of extreme poverty, denied access to natural resources that are necessary for basic sustenance, and so on - can be directly ascribable to the agreement. Moreover, to qualify as such in the sense indicated by Pogge, the alleged 'harm' should be avoidable, meaning that A can renounce at least some of the benefits it gets through the worst agreement that B is willing to sign, without incurring human rights deficits itself. And the negative consequences of the agreement for B should be foreseeable by A. Conversely, if one of the aforementioned conditions fails to apply, A cannot be said to violate a negative duty of justice to $B$, no matter how unfair the agreement.

However, the scope of Pogge's theory is not limited to single interactions between global actors, but it is systemic. He maintains that the global order as a whole is harming the global poor, where by global order he refers to the set of institutional and economic rules, both formal and informal, that have been shaped by the most powerful economic agents, both states and non-state agents, in their own interest. Pogge provides several empirical arguments for justifying his normative claim. Developed countries have opened up their markets to foreign products much less than they forced developing countries 
to do, in particular in those sectors in which they are more competitive, namely agriculture and manufacturing (Pogge 2008, pp. 20-21). Corrupted and authoritarian elites of developing countries have been acknowledged by the international community as having the right to issue public debt and dispose of national resources on behalf of the people that they rule undemocratically (Pogge 2008, pp. 118-22). The wealthy people of the world - be they in poor or rich countries - are using a disproportionately large share of natural resources, thus obtaining consistent profits from them, without compensating those other people that have been excluded from the use of these resources, namely the world's poor (Pogge 2008, pp. 207-9). Lastly, world history, in particular in the last couple of centuries, has been marked by forms of exploitation and violent colonialism that have unjustly contributed to creating global inequality (Pogge 2008, pp. 209-10).

All these elements combine to determine a systemic violation of the negative duty of the world's poor not to be avoidably harmed. However, when it comes to devising global policies for realising compensation, Pogge drastically reduces the range of his analysis by focusing exclusively on the over-appropriation of natural resources. Thus, he advocates what he calls the Global Resources Dividend (GRD), a measure that I shall discuss in more detail at the end of Chapter 3 in relation to MDL, and that consists in those individuals yielding profits out of natural resources paying a small tax to a global fund, which in turn is supposed to cover human rights deficits due to poverty worldwide. As an example, he talks about a GRD tax amounting to 3 dollars per barrel of extracted oil and he estimates that world poverty could be reverted through an annual investment of 300 billion dollars, which amounts to only 0.67 per cent of global GDP in 2005 (Pogge 2008, pp. 210-14).

Pogge's theory will recur in several places in the course of this book, but what I can say for now is the following. Although both Pogge's theory and MDL appeal to negative duties of justice to advocate a global redistribution of wealth, and as we shall see in a while both do so on subjunctive rather than diachronic grounds, the former proposes a poverty-based criticism of inequality in the distribution of natural resources, holding that inequality is bad because it causes the world's poor to be poor, while MDL launches a freedom-based criticism of inequality, according to which inequality is bad because it renders those lacking resources unfree, regardless of their welfare level. Moreover, while Pogge deploys many convincing empirical arguments for justifying the violation of the specific negative duty he has in mind - not to cause harm - paradoxically his compensatory policy is based on the weakest of his theoretical justifications, namely the over-appropriation of natural resources. This argument is inextricably linked to a normative theory of justice in acquisition, which Pogge interprets in Lockean terms, and this risks watering down the stringency to which he aspires by recurring to negative instead of positive 
rights. In other words, if it is quite uncontested in every political and moral philosophy that it is bad to do harm to someone else when this can be avoided and causes a net loss of global welfare, it is not so commonplace that the current distribution of resources should be evaluated, from a normative point of view, in relation to the hypothetical distribution we would have if something like the Lockean proviso had be respected from the start.

All in all, I feel in line with the critical approach that Pogge was the first to adopt with respect to world poverty, arguing that before wondering what we could do to benefit the world's poor, we should ask what we could do to stop harming them. As I said, and as I will stress later on, Pogge's theory and MDL look at two different kinds of harm, and nothing entails that the two approaches are mutually exclusive. Quite the opposite, I believe they can be complementary in providing a comprehensive analysis of the forms of injustice that those individuals who monopolise the means of production perpetrate over those others who, to put it in Marxian terms, only own their labour performance and enjoy the freedom of disposing of it. This gives me the chance to clarify another important issue. The theory based on MDL comes before the theories of justice based on positive duties but does not replace them. Accordingly, I argue that before discussing how we should split social wealth, we should ensure that all those people who take part in the production process do so as a truly voluntary choice - that is to say, not simply free from interactional domination but also from capitalist structural domination. Yet, I do not deny that after (and/or in parallel to) guaranteeing freedom from domination, we should also devise positive principles of distributive justice. I simply remain neutral with regard to the latter, at least in this book, because I do not want to disperse the argumentative focus.

\section{GLOBAL INEQUALITY AND CONVERGENT GLOBALISATION}

Both positive and negative theories of justice are usually welfare-sensitive. They look at the current distribution of world resources and opportunities and argue that it is more or less just, depending on how close it comes to or how far it deviates from a normative ideal, and the correspondence between the actual distribution and the ideal one varies with the variation of individual welfare. In plain words, if we take as an example a society in which there are only three persons, $\mathrm{A}, \mathrm{B}$ and $\mathrm{C}$, and assume that $\mathrm{A}$ and $\mathrm{B}$ are very well off, while $\mathrm{C}$ is poor, I believe that every theory of justice would hold that any change that makes $\mathrm{C}$ better off goes in the direction of the underlying normative ideal - be it sufficiency, equality, the maximisation of utility, a compensation for injustice, and so on. 
Welfare-sensitiveness is apparently reasonable, and I have no intention to criticise it. My point is that we should not just be content with it, because it is insensitive to some forms of domination that are essential for assessing the justice of a particular social order. Let us assume that $\mathrm{C}$ is poor and gets her small income from some assets she controls -cattle, a field, the renting of a small business premises. Let us assume now that $\mathrm{A}$ and $\mathrm{B}$ subtract from $\mathrm{C}$ the few assets at her disposal and offer her the possibility to work for them, and through this change in conditions $\mathrm{C}$ becomes richer than she was before. If $\mathrm{C}$ is made better off than she was before, I guess that very few people would complain. Yet, it should also be noted that as a wage-worker $\mathrm{C}$ is no longer able to unilaterally control the minimum income she was able to obtain before; rather, her entire income - although being now higher - becomes dependent on the willingness of both $\mathrm{A}$ and $\mathrm{B}$ to hire out her labour performance. From this it follows that $\mathrm{A}$ and $\mathrm{B}$ are now in a position to obtain from $\mathrm{C}$ things that they could not obtain before, because they can exert on $C$ the leverage of the hunger risk that was inaccessible to them in the antecedent scenario. In short, $\mathrm{C}$ is now better off but at the same she is more dominated in comparison with her previous situation.

We are speculating here on a closed society with only three individuals, in which $\mathrm{C}$ cannot look for other employers and there are no public subsidies. Yet, someone might object that even in this hypothetical situation she would prefer to rent out her labour performance to others rather than be free but poorer. This is a legitimate claim, and I guess that the majority of people who can get an acceptable income through waged work are quite happy about their condition, or at least would not trade it for a lower but self-sufficient income. Indeed, my criticism is not diachronic but subjunctive. It does not consist in regretting a past situation, or in imagining a more or less realistic Arcadian history; rather, it aims at correcting for forms of injustice that arise in the transition from one state of affairs to another, even though the transition is all things considered favourable. ${ }^{4}$ Thus, when considering our previous example, I am not contending that $\mathrm{C}$ should go back to the initial situation, where she was poorer. I am arguing, instead, that in her new and all things considered better situation, $\mathrm{C}$ should be freed from domination, when this is achievable without others incurring insurmountable costs. The normative reason is that individual autonomy is a free-standing normative ideal that lays down widespread negative duties of justice. To be more precise, the normative strength of the claim that $\mathrm{C}$ should be now free from domination does not depend on the fact that she was free before. When I look at capitalist domination in historical

4 On the difference between a diachronic and a subjunctive treatment of harm I am indebted to Pogge (2008, pp. 23-6) and Meyer (2003). 
terms, in the course of this book, I shall simply do so to understand how the phenomenon has arisen and how it has evolved during the years, but I will never engage in normative arguments based on historical injustice.

The problem with the welfare-sensitiveness of classic theories of justice is that once $\mathrm{C}$ passes to the new condition, and more generally, the wealthier $\mathrm{C}$ gets, the more it becomes difficult for anyone to hold that there is something morally wrong in C's condition. Let us imagine that after a few years of paid work, $\mathrm{C}$ gets the same monthly income as A and B. More precisely, we could assume that the three individuals make the following agreement. A and B will keep on controlling the only means of production available in our hypothetical closed society, and they are willing to hire them out because they would like to minimise physical work, while $\mathrm{C}$ is ready to provide her labour performance. The agreement is initialled and the overall output that the society yields in this way is equally distributed. Any theory of justice that focuses on the fairness of the distribution - be it of resources, opportunities or capabilities - or on the maximisation of a value - be it utility, priority-amended utility, and so on - or on compensating for injustice in appropriation, would look positively at this egalitarian scheme. Yet, what they would not be able to give the right normative weight to is that $\mathrm{A}$ and $\mathrm{B}$ can do without $\mathrm{C}$, but $\mathrm{C}$ cannot do without $\mathrm{A}$ and $\mathrm{B}$. The latter can lay off $\mathrm{C}$, return to work and not suffer income loss, while $\mathrm{C}$ would literally starve in the medium run.

We are here arbitrarily assuming that in this closed society wage-income cannot be turned into productive assets. This could happen, for example, if on a desert island $\mathrm{A}$ and $\mathrm{B}$ controlled the only available fields and cattle, let $\mathrm{C}$ work on them and paid her in vegetable and dairy products - so that at the end of the month A, B and C all have exactly the same quantity of food. Thus, if we move from the envisaged experiment to real life, we should relax the assumption of closeness and accept that a high wage income can be turned into productive assets, and hence move in the direction of labour de-commodification and limit capitalist domination - e.g. wage income can be invested in financial products or used to buy means of production. Accordingly, the shortcoming of welfare-sensitive approaches to justice would be apparent only in social schemes that remain inegalitarian and in which proletarians like $\mathrm{C}$ are simply paid what they need to 'reproduce themselves', that is to say, to rent a small house, buy food and make some modest weekly outings. Nonetheless, I considered it important to give the example of this envisaged experiment to show that even within a society in which income is equally allocated there can be capitalist domination. ${ }^{5}$ Moreover, we should also note that the envisaged

5 It might be objected that the society I have described is not fully egalitarian because even though income is shared equally, A and B have private property, while C 
experiment does not even describe the whole dire situation of real-life proletarians, for $\mathrm{C}$ is the only individual $\mathrm{A}$ and $\mathrm{B}$ can rely upon to avoid engaging directly in full-time work, and this creates some bargaining margins for C. If we want to make this situation more similar to the real one, we should introduce some other individuals (D, E, F and so on) who are extremely poor and have no access to the means of production, and who would be glad to take C's place were she to give up or be laid off.

In saying that welfare-sensitiveness is not enough for assessing the justice of a given distribution of resources, my purpose is to not get lost in mental speculations. Rather, I want to underline that its critical leverage can happen to be drastically reduced in a situation where economic flows reverse an existing inegalitarian trend. This is exactly what is occurring with globalisation, which has been divergent for almost two centuries and from the 1980s has become convergent (Baldwin 2016; Milanovic 2016). From the Industrial Revolution onwards, that is to say from the first half of the nineteenth century, modern economic growth has determined the first inequalities between countries, namely between those who achieved industrialisation and entered the global market and those who did not, at least not immediately. To be more precise, before the Industrial Revolution there was negligible growth in the course of human history. We could say that living conditions never changed substantially from one century to the next, the only exceptions being some technological innovations such as sailing boats, the plough, the press, and so forth, whereas from the introduction of the steam engine onwards, new technologies have progressively increased labour productivity, thus maintaining constant economic growth rates never seen before (Maddison 2005).

Obviously, inequality has always existed in human history, and if we look at both ancient and modern history we would not have many difficulties in bringing to mind cases of enormous injustices in the allocation of resources and opportunities of life. But inequality was mostly a domestic issue, meaning that despite the income gap between the rich and the poor in a given society being surely high, there was not so much difference - at least from an income level - in being poor in one country rather than in another one. From the Industrial Revolution onwards, inequality became also a global problem. Global inequalities became even more pronounced after the Second World War, when the Western bloc boomed, the Soviet Union could not keep up the rate of economic growth and both Africa and South Asia lagged far behind (Milanovic 2016).

has not. However, my conclusions regarding the imperviousness of capitalist domination would remain unchanged, even if we imagined that $\mathrm{C}$ was given more income than both $\mathrm{A}$ and $\mathrm{B}$, so rebalancing the gap in private property. 
It is exactly in these historical contingencies that the normative problem of global justice flourished, in both its practice-dependent and practice-independent versions (see Abizadeh 2007; Sangiovanni 2008; Ronzoni 2009). From the first perspective, the basic argument of global justice was quite linear, as we have already seen. Global markets allow the maximisation of industrial-led growth and it is unfair that this cooperative surplus should be unequally distributed. Obviously, the normative strength of this argument does not depend solely on the fact that some countries industrialised while others did not; rather, it rests also on the contingency that people from poor countries and people from rich ones were enmeshed in a common web of production and trade, and that this web is so extensive and its effects are so pervasive that it can be compared to a domestic scheme of social cooperation (Beitz 1999, pp. 125-76; Moellendorf 2002, pp. 30-67; James 2012). Conversely, the practice-independent version moved from the less controversial empirical claim that some areas of the world are extremely wealthy, while some others are wretched with dire poverty. Therefore, any transfer of resources from the former to the latter would meet a normative criterion, be it to guarantee every human being a set of basic capabilities (Nussbaum 2006), to maximise global utility (Singer 1972), and so on.

From the 1980s onwards, the global economic trend has reversed. Developing countries have continued growing faster than developed ones, and global poverty has progressively diminished. This occurred mainly because new information technologies have allowed for the delocalisation of investments from developed to developing countries, with a consequent transfer of job opportunities. From this moment on, even though domestic inequalities have continued to increase, inequality between countries has progressively decreased, as has world poverty (Baldwin 2016, pp. 79-110). Some few data can convey the idea. In the period from 1950 to the mid-1970s, US GDP per capita was twenty times higher than Chinese GDP: 20 to 1 . Towards the end of the first decade of the twenty-first century, the ratio was reduced to 4 to 1 (again in favour of the United States), exactly the same ratio that existed between the GDP per capita of the two countries in 1870, at the beginning of capitalist globalisation (Milanovic 2016, p. 130).

Practice-dependent theories of global justice work well, intuitively, as long as the worse off get in proportion a smaller share of the global cooperative surplus than the better off - as is the case in the first phase of globalisation, when the better off were becoming wealthier at a much faster pace than the worse off, or, to put it in other terms, as long as the worse off are the losers of globalisation and the better off are the winners. Yet, convergent globalisation has made everything much more complex. Middle classes in developing countries, in particular in Asia, are winning in comparison with middle classes of developed countries, since the former have had much higher income growth rates than the latter. The richest individuals in developed countries have been 
winning over all the others, given that the transfer of job opportunities from the middle classes of developed countries to the middle classes of developing countries has allowed them to cut labour costs. To this we should also add that plutocrats are also the ones who can mostly invest in automation, to the detriment of human workers in general. Aside from all of this, there is also a group of individuals living in countries where there has never been real and propitious economic growth.

I am not maintaining that convergent globalisation undermines practice-dependent justice as such, but surely it renders it harder to read it in a global perspective, because winners and losers of the global market can no longer be classified on the basis of their geographical location. It is no coincidence that the 'new discontent' of globalisation is now the middle and the lower classes of developed countries (Stiglitz 2017). Paradoxically, the practice-dependent argument can also become hostage to reactionary anti-global rhetoric by those who have turned from winners into losers in the switch from divergent to convergent globalisation. This is usually a sign of misplaced grievance, given that globalisation has never given signs of being dysfunctional, in the sense of being unable to yield enough wealth for all, and the real problem is rather that an extremely samll percentage of human beings is taking almost half the available wealth (Oxfam 2020). In a few words, against the welfare sensitiveness of practice-dependent accounts of justice, it might be objected that if the worse off are catching up, in terms of welfare, with the better off, globalisation is already moving in the right direction, and the real social challenge does not consist in a global redistribution of resources, but rather in a class struggle between lower and middle classes on the one hand and plutocrats on the other, that is, internal to developed countries (Corvino 2019c).

The same discourse holds true for practice-independent accounts. Extreme poverty has been declining in the world since the 1980s, both in absolute and in relative terms. In 1980 there were more than 1.9 billion people in extreme poverty in the world. In 2015 the figure was less than 800 million (Our World in Data 2019). If we look at the issue from a broader historical perspective, we may note that at the outset of the Industrial Revolution, in 1820,80 per cent of the world's population was in absolute poverty, while nowadays the number has fallen to 10 per cent (Roser 2017). Some people object that the history of poverty decline cannot be generalised to include the whole world because it is mostly related to the astounding economic growth in China. As a matter of fact, at the beginning of the 1980s almost 88 per cent of Chinese people were in conditions of extreme poverty, while today only 2 per cent remain below this poverty threshold (Roser 2017). Accordingly, given that the Chinese population accounts for slightly less than 20 per cent of the global total, it is obvious that such a blatant decline of poverty in China has had a decisive impact on 
the decline of poverty in the world. However, it suffices to look at a chart on the evolution of world poverty, both with and without China, to realise that from the 1980s world poverty has been declining independently from China. Moreover, as rightly noted by the World Bank, after 2005 world poverty has been higher in percentage terms if we include China than if we exclude it meaning that extreme poverty has been so limited in China over the last 15 years, that the Chinese impact on the constant decline of world poverty has been almost negligible (Roser 2017).

Owing to this empirical evidence, it gets very complicated for practice-independent theorists to play a critical role with regard to globalised capitalism. More concretely, they may express well-grounded moral concerns regarding the fact that a consistent number of people continue to live in dire conditions and well-off people could avoid this at a very low price - considering for example how little money the poor would need to substantially improve their welfare and increase their life chances, and how much money the rich spend on unnecessary things (Singer 2010). Yet they fall short of elaborating a political critique of the global order, that is to say in assigning causal responsibility to the well off for the fact that some people are still very badly off. The same discourse holds true for negative theorists of global justice, as long as the latter rely on the empirical premise that global norms and rules are somehow harming the world's poor (Pogge 2008).

Apparently, one theoretical possibility for preserving the normative strength of classic theories of global justice at a time of convergent globalisation might consist in holding that world poverty is declining despite the current global order, rather than because of it (Pogge 2008, pp. 19-23). The argument could be elaborated, for example, in the sense that industrialisation and openness to world trade are beneficial per se, yet powerful state and non-state actors have shaped the global order so as to collect a relatively disproportionate amount of the collective benefits. Thus, it might be said, world poverty is surely declining, but it could decline even faster if it were not for the injustice perpetrated by the well off. However, also this discourse risks being over-moralised, because it would entail that the global order, that is to say the way in which global capitalism is administered, is all things considered beneficial for the world's poor, but not sufficiently beneficial with respect to a normative ideal of fair cooperation - e.g. the world's poor are getting less benefits than they would get if global economic rules were decided behind a global veil of ignorance (Moellendorf 2002, pp. 70-72; Caney 2005, pp. 125-31).

The normative critique I shall develop, instead, is not limited to the global order but targets the same global capitalism, and it can do this because it is not based on a welfare-sensitive setting. Consequently, its scope is not curtailed by convergent globalisation, at least as long as the latter does not yield diffuse wealth - in addition to relieving extreme poverty. Global capitalism 
undermines individual freedom even when both world inequality and poverty drop. The two phenomena are not necessarily antithetical; on the contrary, the opposite usually occurs. The people who are pulled out of extreme poverty are normally taken away from rural, semi-rural or slum contexts and given a wage contract in the industrial or service sectors. As a consequence, their margins for bargaining are very narrow and their dependence on wage income is extreme. In sum, the economic fluxes that render globalisation convergent are probably all things considered favourable - meaning that it is perhaps preferable to be above the threshold of extreme poverty and more dominated in a capitalistic fashion than being below the threshold and slightly less dominated - but this does not necessarily render people less commodified; in actual fact, quite the opposite is true. 